\title{
Mortality among patients with frequent emergency department use for alcohol-related reasons in Ontario: a population-based cohort study
}

\author{
Jennifer Hulme MD MPH, Hasan Sheikh MD, Edward Xie MD MSc, Evgenia Gatov MPH, \\ Chenthila Nagamuthu MPH, Paul Kurdyak MD PhD
}

Cite as: CMAJ 2020 November 23;192:E1522-31. doi: 10.1503/cmaj.191730

\begin{abstract}
BACKGROUND: Little is known about the risk of death among people who visit emergency departments frequently for alcohol-related reasons, including whether mortality risk increases with increasing frequency of visits. Our primary objective was to describe the sociodemographic and clinical characteristics of this high-risk population and examine their 1-year overall mortality, premature mortality and cause of death as a function of emergency department visit frequency in Ontario, Canada.
\end{abstract}

METHODS: We conducted a populationbased retrospective cohort study using linked health administrative data (Jan. 1, 2010, to Dec. 31, 2016) in Ontario for people aged $16-105$ years who made at least 2 emergency depart- ment visits for mental or behavioural disorders due to alcohol within 1 year. We subdivided the cohort based on visit frequency (2, 3 or 4 , or $\geq 5)$. The primary outcome was 1-year mortality, adjusted for age, sex, income, rural residence and presence of comorbidities. We examined premature mortality using years of potential life lost (YPLL).

RESULTS: Of the 25813 people included in the cohort, 17020 (65.9\%) had 2 emergency department visits within 1 year, $5704(22.1 \%)$ had 3 or 4 visits, and 3089 $(12.0 \%)$ had 5 or more visits. Males, people aged 45-64 years, and those living in urban centres and lower-income neighbourhoods were more likely to have 3 or 4 visits, or 5 or more visits. The all-cause 1-year mortality rate was $5.4 \%$ overall, ranging from $4.7 \%$ among patients with 2 visits to $8.8 \%$ among those with 5 or more visits. Death due to external causes (e.g., suicide, accidents) was most common. The adjusted mortality rate was 38\% higher for patients with 5 or more visits than for those with 2 visits (adjusted hazard ratio 1.38, 95\% confidence interval 1.19-1.59). Among 25298 people aged $16-74$ years, this represented 30607 YPLL.

INTERPRETATION: We observed a high mortality rate among relatively young, mostly urban, lower-income people with frequent emergency department visits for alcohol-related reasons. These visits are opportunities for intervention in a high-risk population to reduce a substantial mortality burden.
A Icohol is a leading driver of morbidity and mortality worldwide. ${ }^{1}$ An estimated 3 million deaths in $2016-$ $5 \%$ of all global deaths - were attributable to alcohol consumption. ${ }^{2}$ The 2016 Global Burden of Disease Study showed that alcohol was the single greatest risk factor for ill health worldwide among people aged 15-49 years. ${ }^{3}$ In Canada, hospital admissions for alcohol-attributable conditions outnumber those for myocardial infarction. ${ }^{4}$ Alcohol-related harms cost Canadians about $\$ 14.6$ billion annually, with $\$ 3.3$ billion in health care costs. ${ }^{5}$
In addition to the societal impact of mental and behavioural disorders due to alcohol (henceforth referred to as alcoholrelated) - mainly acute intoxication and withdrawal - these disorders are common reasons for emergency department visits. 6,7 Data from the United States and Canada, furthermore, suggest that alcohol-related emergency department visits have increased in recent years. ${ }^{8,9}$ For example, a study in Ontario showed that, between 2003 and 2016, the age-standardized rates of alcohol-attributable emergency department visits increased by $86.5 \%$ in women and $53.2 \%$ in men. ${ }^{8}$ People who 
visit emergency departments frequently for alcohol-related reasons have high levels of comorbidity and social disadvantage,,$^{10,11}$ and represent a readily identifiable patient population for whom interventions to address unmet social and health care needs could be developed. ${ }^{12-14} \mathrm{~A}$ systematic review suggested that screening and brief intervention for alcohol-related problems in the emergency department is a promising approach for reducing problematic alcohol consumption. ${ }^{13}$

Despite this, little is known about the risk of death, a key outcome for health system performance, among people who use emergency departments frequently for alcohol-related reasons, including whether mortality risk increases with increasing frequency of visits. To address this gap, our primary objective was to describe the sociodemographic and clinical characteristics of this high-risk population and examine their 1-year overall mortality, premature mortality and cause of death as a function of emergency department visit frequency in Ontario, the most populous Canadian province. ${ }^{15}$

\section{Methods}

\section{Study design and setting}

We conducted a retrospective population-based cohort study of all residents aged 16-105 years in Ontario (population 13.5 million in $2016^{15}$ ) who made frequent emergency department visits for alcohol-related reasons between Jan. 1, 2010, and Dec. 31, 2016.

\section{Data sources}

We used the Registered Persons Database, the central population registry that enables linkage across health administrative data sets, to identify all residents covered under Ontario's publicly funded health insurance and to ascertain sociodemographic characteristics. We obtained information on emergency department use from the National Ambulatory Care Reporting System, and on hospital admissions from the Canadian Institute for Health Information Discharge Abstract Database and the Ontario Mental Health Reporting System, which contains information on all designated psychiatric beds in Ontario. We also used the Office of the Registrar General Deaths data set to ascertain cause of death. These data sets were linked by means of unique encoded identifiers and analyzed at ICES, an independent, nonprofit research institute.

\section{Study population}

In the absence of validation studies for ascertaining a cohort of frequent users of the emergency department for alcohol-related reasons, we relied on previous work examining a broader set of alcohol-attributable conditions. ${ }^{4,8}$ To generate a sample of people who presented for alcohol use disorder issues (and not medical complications of chronic alcohol use), which could inform the development of interventions, we used a subset of alcoholattributable diagnostic codes, selecting code F10 (alcoholrelated mental and behavioural disorders) of the enhanced Canadian version of the International Classification of Diseases and Related Health Problems, 10th Revision (ICD-10-CA) as the main reason for the emergency department visit. We defined frequent users as having had at least 2 unscheduled emergency department visits with ICD-10-CA code F10 within a 1-year time frame. A 2010 review showed that definitions of frequent emergency department use can vary from 2 to 12 visits per year. ${ }^{16}$ We used the minimum threshold to yield a higher-sensitivity sample that reflected our population of interest.

To generate the cohort, we first identified emergency department visits, then identified the unique patients attached to those visits. Of all unscheduled alcohol-related visits within the study period, we restricted potential index events to those that were preceded by at least 1 additional visit within a 365-day time frame to establish a minimum annual visit frequency. Visits during which the patient died were excluded. Since multiple index visits per person were possible, we randomly selected a visit for each person represented within the frequent emergency department visit sample to arrive at a cohort of unique patients. We then classified this cohort into 3 groups based on the total frequency of alcohol-related visits in a 1-year look-back from index: 2 visits (i.e., minimum cohort-entry criterion), 3-4 visits, and 5 or more visits.

\section{Outcomes}

The primary outcome was all-cause mortality 1 year following the index alcohol-related emergency department visit. We report crude and age- and sex-standardized rates (standardized to the 2006 Ontario population by means of the direct method). ${ }^{17}$ Given recent evidence of increasing alcohol-related emergency department use among young adults, ${ }^{8}$ we further examined premature mortality by calculating years of potential life lost (YPLL), an estimate of the average years a person would have lived if he or she had not died prematurely. ${ }^{18,19}$ The numerator was the sum of all YPLL, which, for each age group, was calculated as the difference between 75 years and the median age at death, multiplied by the number of deaths. ${ }^{18}$ The denominator comprised people aged 16-74 years. ${ }^{19}$ We then similarly standardized the resulting YPLL rates to enable group comparisons.

We further examined the frequency of causes of death in the cohort using the ICD-10-CA classification system. To comply with our institution's privacy requirements, we present the following ICD-10-CA categories with frequency greater than $5 \%$ : mental and behavioural disorders, diseases of the circulatory system, diseases of the digestive system, and external causes of morbidity and mortality (e.g., accidents, including accidental poisoning, accidental injuries, injuries, intentional self-harm, assault). In addition, we examined cause of death using alcoholattributable ICD-10-CA codes (Appendix 1, Supplemental Table S2, available at www.cmaj.ca/lookup/doi/10.1503/ cmaj.191730/tab-related-content), ${ }^{8}$ as well as ICD-10-CA codes for death by suicide. ${ }^{20}$

\section{Covariates}

To describe the cohort, we captured age, sex, area-based income quintiles, and urban or rural residence using census information. Given the Ontario legal drinking age (19 yr), we examined ages $16-18$ years separately. We ascertained neighbourhood income using individual postal codes at the level of 
dissemination area, the smallest available census geographic unit. We determined whether patients arrived at the emergency department by ambulance at the index visit as a measure of severity. We defined level of acuity as high (triage level I [resuscitation], II [emergent] or III [urgent]) or low (triage level IV [less urgent] or $\mathrm{V}$ [nonurgent]) using the Canadian Triage and Acuity Scale. ${ }^{21}$ In-hospital length of stay was captured if the patient was admitted. We documented the presence of medical and psychosocial comorbidities using the Johns Hopkins Adjusted Clinical Groups System Version 10.0, ${ }^{22}$ whereby patients were assigned up to 32 Aggregated Diagnosis Groups characterizing medical conditions based on their use of health care services in the preceding year.

\section{Statistical analysis}

To compare sociodemographic characteristics across the study groups at the time of the index emergency department visit, we report the largest pairwise standardized difference. To examine mortality at 1-year follow-up, we calculated crude and age- and sex-standardized rates, generated Kaplan-Meier survival curves, and used a multivariable Cox proportional hazards model adjusted for age, sex, income, rural residence, acuity and presence of comorbidities using a weighted score. The inclusion of comorbidities as a weighted score has been validated to have predictive value for mortality and illness burden. ${ }^{22}$ We adjusted for comorbidities to address the potential confounding of frequent emergency department use and death. We also examined total YPLL, as well as crude and age- and sex-standardized rates of YPLL across the study groups. Last, we calculated the frequency of causes of death across the study groups. To minimize the risk of reidentifying patients owing to small cell counts, we present the 5 most frequent causes of death, comparing groups with the $\chi^{2}$ test. We conducted statistical analyses using SAS software version 9.4 (SAS Institute).

Given that problematic alcohol use can also present as medical complications, we conducted a sensitivity analysis examining a more sensitive case definition using a set of ICD-10-CA codes from the Canadian Institute for Health Information indicator "hospitalizations entirely caused by alcohol" as the primary reason for the emergency department visit. ${ }^{4,8}$ We generated a second cohort using the same methods but included all alcoholattributable conditions (Appendix 1, Supplemental Table S2), ${ }^{8}$ and repeated all analyses described above.

\section{Ethics approval}

The use of data in this project was authorized under Section 45 of Ontario's Personal Health Information Protection Act, which does not require review by a research ethics board.

\section{Results}

We identified 337776 unscheduled emergency department visits for alcohol-related mental and behavioural disorders between Jan. 1, 2009, and Dec. 31, 2016. As per our definition of frequent emergency department use, we excluded 177606 visits that were not preceded by another visit within a 365-day look-back
(Figure 1). We further excluded 1402 visits because of data inconsistencies, non-Ontario residency, age younger than 16 or older than 105 years, or death in the emergency department. We also excluded 14273 visits before Jan. 1, 2010, which were used only to fulfill our frequency criterion for potential index visits during the study period. Of the remaining 144495 index emergency department visits, we selected 1 at random for each patient, which resulted in a cohort of 25813 unique patients, of whom 17020 (65.9\%) had 2 visits within a 1-year look-back, 5704 $(22.1 \%)$ had 3 or 4 visits, and $3089(12.0 \%)$ had 5 or more visits within 1 year. For frequency of diagnoses occurring at index, see Appendix 1, Supplemental Table S1.

Patients with 5 or more alcohol-related visits were more likely than those with fewer visits to be male (2208 [71.5\%]), be aged 45-64 (1435 [46.5\%]), live in urban centres (2768 [89.6\%]), live in the lowest-income neighbourhoods (1239 [40.1\%]) and have arrived at the emergency department by ambulance (2071 [67.0\%]) (Table 1). About 1 in 10 patients in this highestfrequency group were admitted to hospital during their index visit, most often with a stay of 1-3 days. Triage acuity did not differ among the frequency groups, and patients with 5 or more visits were less likely than those in lower-frequency groups to have been admitted during their index emergency department visit. The number of medical and psychosocial comorbidities increased significantly with increasing number of emergency department visits.

\section{One-year mortality}

Overall, 1406 deaths (5.4\%) were observed within 1 year of the index emergency department visit (Table 2). The 1-year mortality rate among patients with 5 or more alcohol-related visits was about double that among patients with 2 visits ( $8.8 \%$ v. $4.7 \%$ ). Cox proportional hazards models similarly showed a severity gradient by frequency of emergency department use: compared to patients with 2 visits, patients with 3 or 4 visits and those with 5 or more visits were 7\% (adjusted hazard ratio [HR] 1.07, 95\% confidence interval $[\mathrm{Cl}]$ 0.94-1.21) and 38\% (adjusted HR 1.38, 95\% Cl 1.19-1.59) more likely to die within 1 year, respectively, after adjustment for sociodemographic factors and comorbidities (Figure 2). Among patients aged $16-74$ years $(n=25298)$, there were 30607 YPLL; the age- and sex-adjusted rate was 116.3 (95\% Cl 114.8-117.7) YPLL per 100 patients (Table 2).

\section{Causes of death}

External causes of morbidity and mortality accounted for the highest number of deaths in the cohort within 1 year after the index visit (424 [30.2\%]), followed by diseases of the digestive system (221 [15.7\%]) (Table 3). One hundred people (7.1\%) died by suicide; this represented $23.6 \%$ of external causes of death. Alcohol-attributable codes ${ }^{19}$ accounted for 482 (34.3\%) of all causes of death, with the most frequent conditions being alcohol dependence syndrome, cirrhosis of the liver and accidental poisoning due to alcohol. External causes of death (e.g., accidental poisoning [ICD-10-CA code X45]), were more common in higherfrequency groups $(p=0.04)$, whereas other conditions showed no significant dose response. 




Figure 1: Flow diagram showing cohort creation. For frequency of diagnoses occurring at index, see Appendix 1, Supplemental Table S1. Note: ED = emergency department.

\section{Sensitivity analysis}

Including a broader set of alcohol-attributable conditions resulted in a cohort of 28237 patients (18878 [66.9\%] with 2 visits, 6173 [21.9\%] with 3 or 4 visits, and 3186 [11.3\%] with $\geq 5$ visits). The most common diagnoses at index remained acute alcohol intoxication, harmful use, dependence and withdrawal (Appendix 1, Supplemental Table S2). Sociodemographic characteristics and clinical presentation at index were similar to those of the F10-specific cohort, except that a larger proportion of patients were admitted to hospital at the index visit (17\% v. 13\%) (Table 4). The 1-year mortality rate was higher in the sensitive cohort than in the specific cohort (7.4\% v. $5.4 \%)$, but mortality similarly increased with more frequent emergency department use in the sensitive cohort. Last, in contrast to the specific cohort, diseases of the digestive system accounted for a larger proportion of deaths in the sensitive cohort than external causes 
Table 1: Sociodemographic and clinical characteristics of patients with 2 or more emergency department visits within 1 year for alcohol-related reasons between Jan. 1, 2010, and Dec. 31, 2016

\begin{tabular}{|c|c|c|c|c|c|}
\hline \multirow[b]{2}{*}{ Characteristic } & \multicolumn{4}{|c|}{ No. of ED visits; no. (\%) of patients* } & \multirow[b]{2}{*}{$\begin{array}{r}\text { Standardize } \\
\text { difference }\end{array}$} \\
\hline & $\begin{array}{c}\text { Overall } \\
n=25813\end{array}$ & $\begin{array}{c}2 \\
n=17020\end{array}$ & $\begin{array}{c}3-4 \\
n=5704\end{array}$ & $\begin{array}{c}\geq 5 \\
n=3089\end{array}$ & \\
\hline \multicolumn{6}{|l|}{ Sex } \\
\hline Female & $8224(31.9)$ & $5548(32.6)$ & $1795(31.5)$ & $881(28.5)$ & $0.09 \ddagger$ \\
\hline Male & $17589(68.1)$ & $11472(67.4)$ & $3909(68.5)$ & $2208(71.5)$ & $0.09 \ddagger$ \\
\hline \multicolumn{6}{|l|}{ Age at index ED visit, yr } \\
\hline Mean $\pm S D$ & $43.66 \pm 15.42$ & $43.00 \pm 16.12$ & $45.05 \pm 14.26$ & $44.79 \pm 13.12$ & $0.12 \ddagger$ \\
\hline Median (IQR) & $45(31-55)$ & $44(29-55)$ & $46(34-55)$ & $45(34-54)$ & $0.14 \S$ \\
\hline $16-18$ & $873(3.4)$ & $754(4.4)$ & $103(1.8)$ & $16(0.5)$ & $0.25 \ddagger$ \\
\hline $19-24$ & $2758(10.7)$ & $2181(12.8)$ & $410(7.2)$ & $167(5.4)$ & $0.26 \ddagger$ \\
\hline $25-44$ & $9152(35.5)$ & $5760(33.8)$ & $2117(37.1)$ & $1275(41.3)$ & $0.15 \ddagger$ \\
\hline $45-64$ & $10752(41.6)$ & $6723(39.5)$ & $2594(45.5)$ & $1435(46.5)$ & $0.14 \ddagger$ \\
\hline $65-105$ & $2278(8.8)$ & $1602(9.4)$ & $480(8.4)$ & $196(6.3)$ & $0.11 \ddagger$ \\
\hline \multicolumn{6}{|l|}{ Rural status } \\
\hline Urban & $22590(87.5)$ & $14831(87.1)$ & $4991(87.5)$ & $2768(89.6)$ & $0.08 \ddagger$ \\
\hline Rural & $3223(12.5)$ & $2189(12.9)$ & $713(12.5)$ & $321(10.4)$ & $0.08 \ddagger$ \\
\hline \multicolumn{6}{|l|}{ Neighbourhood income quintile } \\
\hline Q1 (lowest) & $9233(35.8)$ & $5880(34.5)$ & $2114(37.1)$ & $1239(40.1)$ & $0.12 \ddagger$ \\
\hline Q2 & $5384(20.9)$ & $3553(20.9)$ & $1208(21.2)$ & $623(20.2)$ & 0.029 \\
\hline Q3 & $4173(16.2)$ & $2792(16.4)$ & $879(15.4)$ & $502(16.3)$ & $0.03 \S$ \\
\hline Q4 & $3506(13.6)$ & $2415(14.2)$ & $761(13.3)$ & $330(10.7)$ & $0.11 \ddagger$ \\
\hline Q5 (highest) & $3234(12.5)$ & $2226(13.1)$ & $676(11.9)$ & $332(10.7)$ & $0.07 \ddagger$ \\
\hline Missing & $283(1.1)$ & $154(0.9)$ & $66(1.2)$ & $63(2.0)$ & $0.09 \ddagger$ \\
\hline \multicolumn{6}{|l|}{$\begin{array}{l}\text { No. of Johns Hopkins ADG } \\
\text { comorbidities }\end{array}$} \\
\hline Mean \pm SD & $6.18 \pm 3.59$ & $5.57 \pm 3.41$ & $6.79 \pm 3.49$ & $8.44 \pm 3.67$ & $0.81 \ddagger$ \\
\hline Median (IQR) & $6(3-8)$ & $5(3-8)$ & $6(4-9)$ & $8(6-11)$ & $0.85 \ddagger$ \\
\hline \multicolumn{6}{|l|}{ Acuity at index ED visit } \\
\hline High (CTAS triage level I, II or III) & $3338(12.9)$ & $2180(12.8)$ & $717(12.6)$ & $441(14.3)$ & 0.049 \\
\hline Low (CTAS triage level IV or V) & $22317(86.5)$ & $14736(86.6)$ & $4949(86.8)$ & $2632(85.2)$ & $0.05^{\star \star}$ \\
\hline Missing & $158(0.6)$ & $104(0.6)$ & $38(0.7)$ & $16(0.5)$ & $0.02^{\star \star}$ \\
\hline Arrived by ambulance & $15335(59.4)$ & $9941(58.4)$ & $3323(58.3)$ & $2071(67.0)$ & 0.189 \\
\hline Admitted to hospital at index ED visit & $3377(13.1)$ & $2248(13.2)$ & $771(13.5)$ & $358(11.6)$ & $0.06^{\star \star}$ \\
\hline \multicolumn{6}{|l|}{ Hospital length of stay, $\mathrm{d}(n=3377)$} \\
\hline Median (IQR) & $3(1-7)$ & $3(1-7)$ & $3(2-6)$ & $2(1-5)$ & $0.33^{\star \star}$ \\
\hline $1-3$ & $1873(55.5)$ & $1221(54.3)$ & $414(53.7)$ & $238(66.5)$ & $0.26^{\star *}$ \\
\hline $4-6$ & $642(19.0)$ & $408(18.1)$ & $175(22.7)$ & $59(16.5)$ & $0.16^{\star \star}$ \\
\hline 7-9 & $311(9.2)$ & $220(9.8)$ & $66(8.5)$ & $25(7.0)$ & $0.10 \ddagger$ \\
\hline$\geq 10$ & $551(16.3)$ & $399(17.7)$ & $116(15.0)$ & $36(10.0)$ & $0.22 \ddagger$ \\
\hline
\end{tabular}

Note: $\mathrm{ADG}=$ Aggregated Diagnosis Group, $\mathrm{CTAS}=$ Canadian Triage and Acuity Scale, $\mathrm{ED}=$ emergency department, IQR = interquartile range, $\mathrm{SD}=$ standard deviation.

*Except where noted otherwise.

†Pairwise standardized differences were calculated between all study groups. The largest standardized difference is reported as follows: $\ddagger 2$ visits versus 5 or more visits, $§ 2$ visits versus 3-4 visits, ^tie in largest standardized difference between 2 visits versus 5 or more visits and 3-4 visits versus 5 or more visits, ${ }^{\star \star} 3-4$ visits versus 5 or more visits. 


\section{Table 2: Crude and age- and sex-standardized mortality rates and rates of years of potential life lost}

Group; no. of alcohol-related ED visits

No. of patients

No. of deaths 1 yr after index visit

Mortality rate per 100

Age- and sexstandardized mortality rate* $(95 \% \mathrm{CI})$

Overall cohort

$\begin{array}{lcccc}\text { Overall } & 25813 & 1406 & 5.4 & 5.4(5.0-5.7) \\ 2 & 17020 & 799 & 4.7 & 4.8(4.4-5.2) \\ 3-4 & 5704 & 336 & 5.9 & 5.4(4.7-6.2) \\ \geq 5 & 3089 & 271 & 8.8 & 8.4(7.1-10)\end{array}$

Age- and sexstandardized YPLL

Total YPLL 1 yr after index visit

YPLL rate

30607

16064

7498

7044 per 100

121.0

96.6

133.6

231.0 rate per 100 *

$(95 \% \mathrm{Cl})$

$116.3(114.8-117.7)$

92.9 (91.3-94.5)

132.6 (129.0-136.2)

$230.0(222.6-237.7)$

Note: $\mathrm{Cl}=$ confidence interval, $\mathrm{ED}=$ emergency department, $\mathrm{YPLL}=$ years of potential life lost. *Age- and sex-standardized to the 2006 Ontario population by means of the direct method. ${ }^{17}$

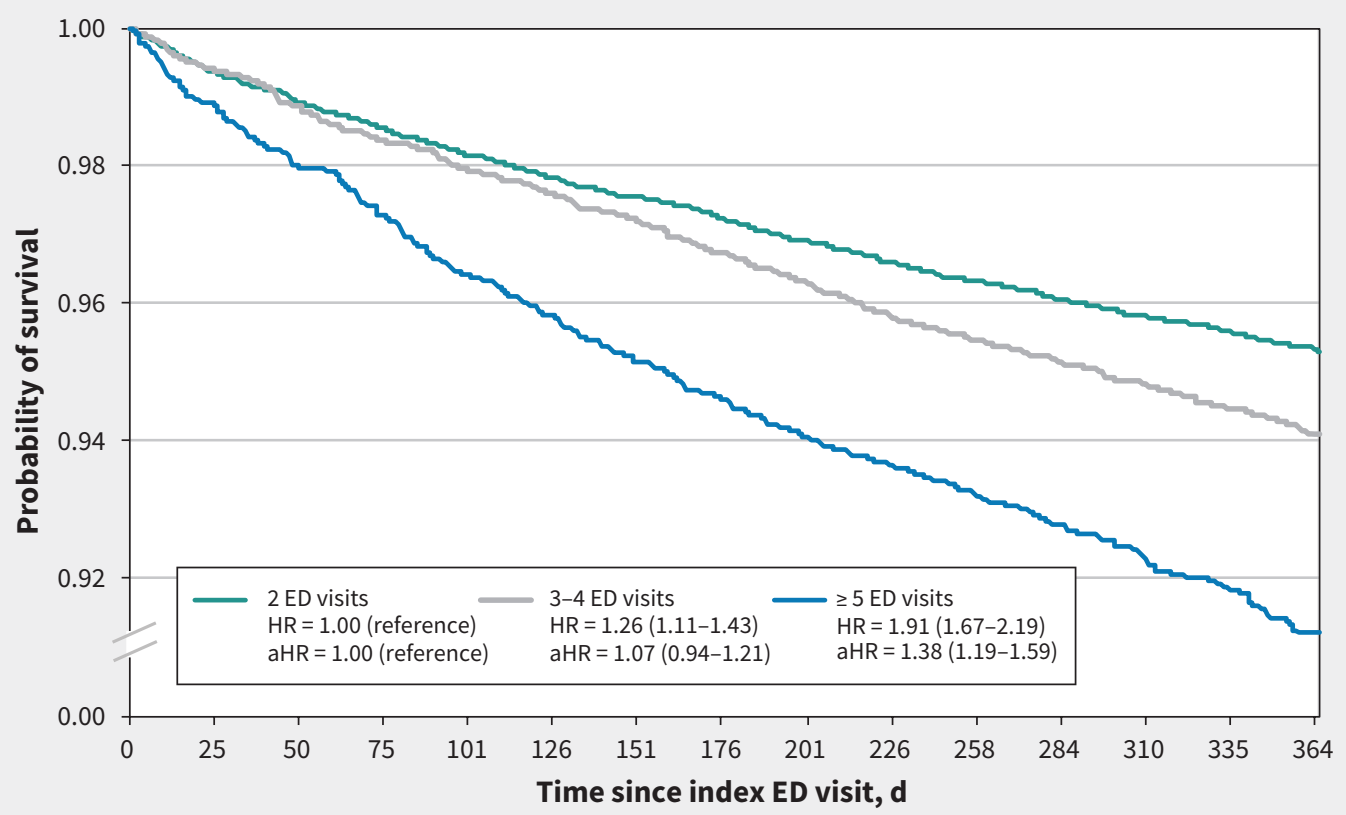

Figure 2: Kaplan-Meier survival plot 1 year after index emergency department (ED) visit. Adjusted and unadjusted hazard ratios are presented with $95 \%$ confidence intervals. Note: aHR $=$ adjusted hazard ratio, $\mathrm{HR}=$ hazard ratio. 
No. of ED visits; no. (\%) of patients*

\begin{tabular}{|c|c|c|c|c|c|}
\hline Cause of death, ICD-10-CA code & $\begin{array}{c}\text { Total } \\
n=1406\end{array}$ & $\begin{array}{c}2 \\
n=799\end{array}$ & $\begin{array}{c}3-4 \\
n=336\end{array}$ & $\begin{aligned} & \geq 5 \\
n & =271\end{aligned}$ & $p$ value \\
\hline F00-F999 Mental and behavioural disorders & $256(18.2)$ & $140(17.5)$ & $62(18.4)$ & $54(19.9)$ & 0.7 \\
\hline 100-1999 Diseases of the circulatory system & $170(12.1)$ & $108(13.5)$ & $35(10.4)$ & $27(10.0)$ & 0.2 \\
\hline K00-K939 Diseases of the digestive system & $221(15.7)$ & $128(16.0)$ & 54 (16.1) & 39 (14.4) & 0.8 \\
\hline V01-Y989 External causes of morbidity and mortality $\dagger$ & $424(30.2)$ & $223(27.9)$ & $111(33.0)$ & $90(33.2)$ & 0.1 \\
\hline $\begin{array}{l}\text { X60-X84 Death by suicide (subset of external causes of } \\
\text { morbidity and mortality) }\end{array}$ & $100(7.1)$ & $60(7.5)$ & $22(6.5)$ & $18(6.6)$ & 0.8 \\
\hline All alcohol-attributable ICD-10-CA codes (\% of this row) ${ }^{4}$ & $n=482$ & $n=258$ & $n=127$ & $n=97$ & \\
\hline $\begin{array}{l}\text { F101 Mental and behavioural disorders due to use of } \\
\text { alcohol, harmful use }\end{array}$ & $52(10.8)$ & $25(9.7)$ & $12(9.4)$ & $15(15.5)$ & 0.2 \\
\hline $\begin{array}{l}\text { F102 Mental and behavioural disorders due to use of } \\
\text { alcohol, dependence syndrome }\end{array}$ & $135(28.0)$ & $71(27.5)$ & $39(30.7)$ & $25(25.8)$ & 0.4 \\
\hline K703 Alcoholic cirrhosis of liver & $80(16.6)$ & $47(18.2)$ & $23(18.1)$ & $10(10.3)$ & 0.2 \\
\hline K704 Alcoholic hepatic failure & $22(4.6)$ & $16(6.2)$ & S & S & 0.3 \\
\hline X45 Accidental poisoning by and exposure to alcohol & $97(20.1)$ & $43(16.7)$ & $29(22.8)$ & $25(25.8)$ & 0.04 \\
\hline \multicolumn{6}{|c|}{ 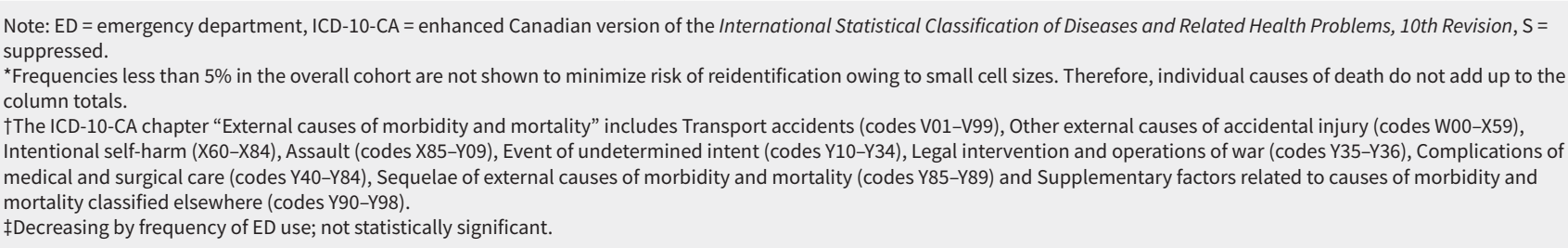 } \\
\hline
\end{tabular}

such as accidents (578/2100 [27.5\%] and 446/2100 [21.2\%], respectively), and the proportion of deaths by suicide was $5.4 \%$. Alcohol-attributable causes of death accounted for a larger proportion of deaths in the sensitive cohort than in the specific cohort (39.2\% v. 34.3\%). There was an increasing trend by frequency of emergency department use for accidental causes of death $(p<0.001)$.

\section{Interpretation}

In this cohort of patients with 2 or more emergency department visits for alcohol-related reasons in a 1-year period, about 1 in 20 patients died within 1 year after the index visit. We found a relation between increasing frequency of emergency department use and mortality, with the 1-year mortality rate for patients with 5 or more visits nearly twice that for patients with 2 visits, even after adjustment for sociodemographic characteristics and comorbidities. External causes of death, including accidental poisoning, suicide and trauma, as well as diseases of the digestive system accounted for the majority of deaths in the cohort.

Although it is known that many people with severe alcohol use disorder are frequent users of emergency departments, ${ }^{8}$ the mortality rate of these people is not well documented. We observed a standardized 1-year mortality rate of $5.4 \%$, which was higher than the 1-year mortality among Dutch patients admitted to intensive care units with alcohol intoxication (4.4\%). ${ }^{23}$ The mortality rate we observed in the highest-frequency group, $8.8 \%$, is comparable to the rate among patients admitted with myocardial infarction in a French study ${ }^{24}$ and is nearly 4 times the rate among people with 5 or more emergency department visits for any substance use in Alberta, 2.3\%. ${ }^{25}$

The relatively young age of our cohort resulted in high premature mortality, with more YPLL than for all patients diagnosed with pneumonia, influenza, bronchitis, emphysema and asthma in Ontario during a similar period. ${ }^{26}$ The high rates of comorbidities and suicide are consistent with previous studies evaluating the impact of alcohol on mortality and morbidity,,$^{1,5,27-30}$ and support the strong link between alcohol use and suicide risk. ${ }^{31}$

The observed young age and high mortality rates, including the high rate in the highest prevalence, lower visit frequency group, are concerning. The clinical interventions required to mitigate this risk are unclear. Frequent visits to the emergency department represent opportunities for timely intervention. ${ }^{32-34}$ Promising strategies include screening, brief intervention, treatment referrals, ${ }^{35}$ managed alcohol programs ${ }^{36}$ and case management. ${ }^{37}$ Rapid access to addiction medicine clinics has been shown to reduce both substance use ${ }^{38}$ and emergency department visits, ${ }^{39}$ and may also have an impact on mortality in frequent users of emergency departments for alcohol-related mental and behavioural disorders. 
Table 4: Characteristics and outcomes of frequent emergency department users for conditions entirely attributable to alcohol use (sensitivity analysis)

No. of ED visits; no. (\%) of patients ${ }^{\star} \dagger$

\begin{tabular}{|c|c|c|c|c|c|}
\hline Characteristic & $\begin{array}{l}\text { Overall } \\
n=28237\end{array}$ & $\begin{array}{l}2 \\
n=18878\end{array}$ & $\begin{array}{c}3-4 \\
n=6173\end{array}$ & $\begin{array}{c}\geq 5 \\
n=3186\end{array}$ & $\begin{array}{c}\text { Standardized } \\
\text { difference§ }\end{array}$ \\
\hline Male sex & $19250(68.2)$ & $12782(67.7)$ & $4224(68.4)$ & $2244(70.4)$ & $0.06 \uparrow$ \\
\hline \multicolumn{6}{|l|}{ Age at index ED visit, yr } \\
\hline Mean \pm SD & $44.03 \pm 15.38$ & $43.57 \pm 16.03$ & $44.95 \pm 14.36$ & $44.91 \pm 13.08$ & $0.09^{\star \star}$ \\
\hline Median (IQR) & $45(31-55)$ & $45(30-55)$ & $46(34-55)$ & $46(34-54)$ & $0.09^{\star \star}$ \\
\hline Urban dweller & $24650(87.3)$ & $16431(87.0)$ & $5358(86.8)$ & $2861(89.8)$ & $0.09 \dagger \dagger$ \\
\hline Lowest neighbourhood income quintile & $9979(35.3)$ & $6412(34.0)$ & $2267(36.7)$ & $1300(40.8)$ & $0.14 \uparrow$ \\
\hline $\begin{array}{l}\text { High acuity at index ED visit (CTAS triage } \\
\text { level I, II or III) }\end{array}$ & $24485(86.7)$ & $16383(86.8)$ & $5345(86.6)$ & $2757(86.5)$ & $0.01^{\star \star}$ \\
\hline Arrived by ambulance & $16313(57.8)$ & $10681(56.6)$ & $3556(57.6)$ & $2076(65.2)$ & 0.18 ฯ \\
\hline \multicolumn{6}{|l|}{ No. of Johns Hopkins ADG comorbidities } \\
\hline Mean \pm SD & $6.35 \pm 3.66$ & $5.78 \pm 3.50$ & $6.96 \pm 3.61$ & $8.53 \pm 3.67$ & 0.77 ฯ \\
\hline Median (IQR) & $6(4-9)$ & $5(3-8)$ & $6(4-9)$ & $8(6-11)$ & 0.81 ฯ \\
\hline Admitted to hospital at index ED visit & $4830(17.1)$ & $3378(17.9)$ & $1077(17.4)$ & $375(11.8)$ & 0.179 \\
\hline \multicolumn{6}{|l|}{ Hospital length of stay, $d$} \\
\hline Mean \pm SD & $7.62 \pm 18.30$ & $7.68 \pm 17.18$ & $7.98 \pm 21.72$ & $6.08 \pm 17.29$ & $0.1 \ddagger \ddagger$ \\
\hline \multirow[t]{2}{*}{ Median (IQR) } & $3(2-7)$ & $4(2-8)$ & $3(2-7)$ & $3(1-5)$ & 0.299 \\
\hline & & & & & $p$ value \\
\hline Death within $1 \mathrm{yr}$ & $2100(7.4)$ & $1314(7.0)$ & $483(7.8)$ & $303(9.5)$ & $<0.001$ \\
\hline Crude HR $(95 \% \mathrm{Cl})$ & NA & Reference & $1.13(1.01-1.25)$ & $1.38(1.21-1.56)$ & $<0.001$ \\
\hline Adjusted HR (95\% Cl) & NA & Reference & $0.95(0.85-1.05)$ & $0.97(0.85-1.10)$ & 0.6 \\
\hline \multicolumn{6}{|l|}{ Cause of death, ICD-10-CA code } \\
\hline $\begin{array}{l}\text { F00-F999 Mental and behavioural } \\
\text { disorders }\end{array}$ & $413(19.7)$ & $260(19.8)$ & $97(20.1)$ & $56(18.5)$ & 0.8 \\
\hline $\begin{array}{l}\text { 100-1999 Diseases of the circulatory } \\
\text { system }\end{array}$ & $206(9.8)$ & $120(9.1)$ & $52(10.8)$ & $34(11.2)$ & 0.4 \\
\hline $\begin{array}{l}\text { K00-K939 Diseases of the digestive } \\
\text { system }\end{array}$ & $578(27.5)$ & $418(31.8)$ & $115(23.8)$ & $45(14.8)$ & $<0.001$ \\
\hline $\begin{array}{l}\text { V01-Y989 External causes of morbidity } \\
\text { and mortality }\end{array}$ & $446(21.2)$ & $230(17.5)$ & $124(25.7)$ & $92(30.4)$ & $<0.001$ \\
\hline $\begin{array}{l}\text { X60-X84 Death by suicide (subset of } \\
\text { external causes of morbidity and } \\
\text { mortality) }\end{array}$ & $113(5.4)$ & $69(5.2)$ & $23(4.8)$ & $21(6.9)$ & 0.4 \\
\hline $\begin{array}{l}\text { All alcohol-attributable ICD-10-CA codes } \\
(\% \text { of this row })^{4}\end{array}$ & $n=823$ & $n=517$ & $n=197$ & $n=109$ & \\
\hline $\begin{array}{l}\text { F101 Mental and behavioural disorders } \\
\text { due to use of alcohol, harmful use }\end{array}$ & $123(14.9)$ & $79(15.3)$ & $30(15.2)$ & $14(12.8)$ & 0.6 \\
\hline $\begin{array}{l}\text { F102 Mental and behavioural disorders } \\
\text { due to use of alcohol, dependence } \\
\text { syndrome }\end{array}$ & $189(23.0)$ & $112(21.7)$ & $48(24.4)$ & $29(26.6)$ & 0.6 \\
\hline K703 Alcoholic cirrhosis of liver & $221(26.8)$ & $163(31.5)$ & $40(20.3)$ & $18(16.5)$ & $<0.001$ \\
\hline K704 Alcoholic hepatic failureł & $41(5.0)$ & $28(5.4)$ & S & $S$ & 0.2 \\
\hline $\begin{array}{l}\text { X45 Accidental poisoning by and } \\
\text { exposure to alcohol }\end{array}$ & $99(12.0)$ & $39(7.5)$ & $35(17.8)$ & $25(22.9)$ & $<0.001$ \\
\hline
\end{tabular}

Note: $\mathrm{ADG}=$ Aggregated Diagnosis Group, $\mathrm{Cl}=$ confidence interval, $\mathrm{CTAS}=$ Canadian Triage and Acuity Scale, $\mathrm{HR}=$ hazard ratio, $\mathrm{ICD}-10-\mathrm{CA}=$ enhanced $\mathrm{Canadian}$ version of the International Statistical Classification of Diseases and Related Health Problems, 10th Revision, IQR = interquartile range, NA = not applicable, $\mathrm{S}=$ suppressed, $\mathrm{SD}=\mathrm{standard}$ deviation. *Except where noted otherwise.

†Frequencies less than $5 \%$ are not shown to minimize risk of reidentification owing to small cell sizes. Therefore, individual causes of death do not add up to the column totals. †Decreasing frequency with increasing ED use; not statistically significant.

§Pairwise standardized differences were calculated between all study groups. The largest standardized difference is reported as follows: $₫ 2$ visits versus 5 or more visits, ${ }^{\star \star}$ tie between 2 visits versus $3-4$ visits and 2 visits versus 5 or more visits, †ttie between 2 visits versus 5 or more visits and $3-4$ visits versus 5 or more visits, $\ddagger \ddagger 3-4$ visits versus 5 or more visits. 


\section{Limitations}

We used ICD-10-CA code F10 to ascertain alcohol use disorders among patients presenting to the emergency department. Although this approach is used by the Canadian Institute for Health Information, it has not been validated. Furthermore, our approach to identifying alcohol use disorders was ad hoc, and although it reflects the clinical scenarios we intended to capture, it has not been validated. Additional work is needed to compare this study population to nonfrequent emergency department users for alcohol-related reasons and to frequent emergency department users for other chronic illnesses. Since our specific cohort focused on people with alcohol-related mental and behavioural disorders as the main reason for the emergency department visit, our study likely underestimates the burden of frequent emergency department use related to alcohol, including both the medical complications of alcohol use and other presentations (e.g., motor vehicle accidents). Our aim, however, was to capture a population with an easily identifiable clinical presentation for whom specific interventions may be targeted. Our sensitivity analysis using a more sensitive case definition illustrated similar increases in mortality as a function of emergency department use. More work is needed to examine alcohol use in secondary diagnoses at emergency department presentation. Finally, we assembled a cohort and imposed an ad hoc severity gradient based on categories of visit frequency. We included this severity gradient to inform the relation between alcohol use and death in the absence of an appropriate control group.

\section{Conclusion}

We identified and characterized a population of patients with frequent emergency department visits for alcohol-related reasons who had a high 1-year mortality rate that increased significantly as a function of emergency department use. A combination of high mortality and low hospital admission rates suggests that frequent emergency department visits in this population signal an unmet need. Given our cohort's relatively young age, effective interventions have the potential to prevent premature mortality and reduce hospital use.

\section{References}

1. Rehm J, Mathers C, Popova S, et al. Global burden of disease and injury and economic cost attributable to alcohol use and alcohol-use disorders. Lancet 2009;373:2223-33.

2. Global status report on alcohol and health 2018. Geneva: World Health Organization; 2018.

3. GBD 2016 Risk Factors Collaborators. Global, regional, and national comparative risk assessment of 84 behavioural, environmental and occupational, and metabolic risks or clusters of risks, 1990-2016: a systematic analysis for the Global Burden of Disease Study 2016. Lancet 2017;390:1345-422.

4. Alcohol harm in Canada: examining hospitalizations entirely caused by alcohol and strategies to reduce alcohol harm. Ottawa: Canadian Institute for Health Information; 2017.

5. Rehm JBD, Brochu S, Fischer B, et al. The costs of substance abuse in Canada 2002. Ottawa: Canadian Centre on Substance Abuse; 2006.

6. Hunt KA, Weber EJ, Showstack JA, et al. Characteristics of frequent users of emergency departments. Ann Emerg Med 2006;48:1-8.

7. Liu SW, Nagurney JT, Chang Y, et al. Frequent ED users: Are most visits for mental health, alcohol, and drug-related complaints? Am J Emerg Med 2013; 31:1512-5.
8. Myran DT, Hsu AT, Smith G, et al. Rates of emergency department visits attributable to alcohol use in Ontario from 2003 to 2016: a retrospective populationlevel study. CMAJ 2019;191:E804-10.

9. Mullins PM, Mazer-Amirshahi M, Pines JM. Alcohol-related visits to US emergency departments, 2001-2011. Alcohol Alcohol 2017;52:119-25.

10. Doupe MB, Palatnick W, Day S, et al. Frequent users of emergency departments: developing standard definitions and defining prominent risk factors. Ann Emerg Med 2012;60:24-32.

11. Moriarty K, Cassidy P, Dalton D, et al. Alcohol-related disease: meeting the challenge of improved quality of care and better use of resources. London (UK): British Society of Gastroenterology; 2010.

12. Malone RE. Heavy users of emergency services: social construction of a policy problem. Soc Sci Med 1995;40:469-77.

13. D'Onofrio G, Degutis LC. Preventive care in the emergency department: screening and brief intervention for alcohol problems in the emergency department: a systematic review. Acad Emerg Med 2002;9:627-38.

14. Crawford MJ, Patton R, Touquet R, et al. Screening and referral for brief intervention of alcohol-misusing patients in an emergency department: a pragmatic randomised controlled trial. Lancet 2004;364:1334-9.

15. 2016 census highlights: Factsheet 1 . Oshawa (ON): Ontario Ministry of Finance; 2017.

16. LaCalle E, Rabin E. Frequent users of emergency departments: the myths, the data, and the policy implications. Ann Emerg Med 2010;56:42-8.

17. Ahmad OB, Boschi-Pinto C, Lopez AD, et al. Age standardization of rates: a new WHO standard. Geneva: World Health Organization; 2001:9.

18. Data quality, concepts and methodology. 2. Health status indicators based on vital statistics (2.2.9). Ottawa: Statistics Canada; 2007. Cat no 82-221XWE2007001. Available: www.statcan.gc.ca/pub/82-221-x/2013001/quality -qualite/qua2-eng.htm (accessed 2016 July 26).

19. Health indicators 2012. Ottawa: Canadian Institute for Health Information; 2012. Available: https://secure.cihi.ca/free_products/health_indicators_2012_ en.pdf (accessed 2016 July 27).

20. Gatov E, Kurdyak P, Sinyor M, et al. Comparison of vital statistics definitions of suicide against a coroner reference standard: a population-based linkage study. Can J Psychiatry 2018;63:152-60.

21. Mirhaghi A, Heydari A, Mazlom R, et al. The reliability of the Canadian Triage and Acuity Scale: meta-analysis. N Am J Med Sci 2015;7:299-305.

22. Austin PC, Walraven C. The Mortality Risk Score and the ADG score: two points based scoring systems for the Johns Hopkins Aggregated Diagnosis Groups to predict mortality in a general adult population cohort in Ontario, Canada. Med Care 2011;49:940-7.

23. Brandenburg R, Brinkman S, de Keizer NF, et al. In-hospital mortality and longterm survival of patients with acute intoxication admitted to the ICU. Crit Care Med 2014;42:1471-9.

24. Puymirat E, Schiele F, Steg PG, et al. Determinants of improved one-year survival in non-ST-segment elevation myocardial infarction patients: insights from the French FAST-MI program over 15 years. Int J Cardiol 2014;177:281-6.

25. Moe J, Camargo CA, Davis RB, et al. Frequent emergency department use and mortality in patients with substance and opioid use in Alberta: a populationbased retrospective cohort study. CJEM 2019;21:482-91.

26. Table 13-10-0742-01: mortality and potential years of life lost, by selected causes of death and sex, three-year average, Canada, provinces, territories, health regions and peer groups occasional (number). Ottawa: Statistics Canada; 2018. Available: https://www150.statcan.gc.ca/t1/tbl1/en/tv.action?pid=1310074201 (accessed 2018 Dec. 20).

27. Fegan S. Recommended ICD-10-CA codes for injury core indicators. Ontario: Association of Public Health Epidemiologists in Ontario; 2013. Available: http://core. apheo.ca/index.php?pid=306 (accessed 2018 Jan. 3).

28. Patra J, Taylor B, Rehm J. The disease burden of alcohol consumption. CMAJ 2007;177:65.

29. Rehm J, Klotsche J, Patra J. Comparative quantification of alcohol exposure as risk factor for global burden of disease. Int J Methods Psychiatr Res 2007;16:66-76.

30. Rehm J, Taylor B, Roerecke M, et al. Alcohol consumption and alcohol-attributable burden of disease in Switzerland, 2002. Int J Public Health 2007;52:383-92.

31. Dwyer-Lindgren L, Bertozzi-Villa A, Stubbs RW, et al. Trends and patterns of geographic variation in mortality from substance use disorders and intentional injuries among US counties, 1980-2014. JAMA 2018;319:1013-23.

32. Parkman T, Neale J, Day E, et al. Qualitative exploration of why people repeatedly attend emergency departments for alcohol-related reasons. BMC Health Serv Res 2017;17:140.

33. Brubacher JR, Mabie A, Ngo M, et al. Substance-related problems in patients visiting an urban Canadian emergency department. CJEM 2008;10:198-204. 
34. Shumway M, Boccellari A, O'Brien K, et al. Cost-effectiveness of clinical case management for ED frequent users: results of a randomized trial. Am J Emerg Med 2008;26:155-64.

35. Bernstein SL, D'Onofrio G. A promising approach for emergency departments to care for patients with substance use and behavioral disorders. Health Aff (Millwood) 2013;32:2122-8.

36. Vallance K, Stockwell T, Pauly B, et al. Do managed alcohol programs change patterns of alcohol consumption and reduce related harm? A pilot study. Harm Reduct J 2016;13:13.
37. Kumar GS, Klein R. Effectiveness of case management strategies in reducing emergency department visits in frequent user patient populations: a systematic review. J Emerg Med 2013;44:717-29.

38. Wiercigroch $\mathrm{D}$, Sheikh $\mathrm{H}$, Hulme J. A rapid access to addiction medicine clinic facilitates treatment of substance use disorder and reduces substance use. Subst Abuse Treat Prev Policy 2020;15:4.

39. Corace K, Willows M, Schubert N, et al. Alcohol medical intervention clinic: a rapid access addiction medicine model reduces emergency department visits. J Addict Med 2020;14:163-71.

\section{Competing interests: None declared.}

This article has been peer reviewed.

Affiliations: University Health Network (Hulme, Sheikh, Xie); Department of Family and Community Medicine (Hulme, Sheikh, Xie), University of Toronto; ICES (Gatov, Nagamuthu, Kurdyak); Institute for Mental Health Policy Research (Kurdyak), Centre for Addiction and Mental Health, Toronto, Ont.

Contributors: Jennifer Hulme, Hasan Sheikh and Edward Xie contributed equally to the study. Paul Kurdyak supervised the study. Jennifer Hulme, Hasan Sheikh, Edward Xie, Evgenia Gatov and Paul Kurdyak conceived and designed the study. Chenthila Nagamuthu analyzed the data. Jennifer Hulme, Hasan Sheikh, Edward Xie, Evgenia Gatov and Paul Kurdyak drafted the manuscript. All of the authors interpreted the data, revised the manuscript critically for important intellectual content, approved the final version to be published and agreed to be accountable for all aspects of the work.

Funding: This study was supported by ICES, which is funded by an annual grant from the Ontario Ministry of Health and Long-Term Care (MOHLTC). It was also supported by a Mental Health and Addictions Scorecard and Evaluation Framework grant (04601A14-19) from the MOHLTC. Paul Kurdyak is supported in part by the Medical Psychiatry Alliance, a collaborative health partnership of the University of Toronto, the Centre for Addiction and Mental Health, The Hospital for Sick Children, Trillium Health Partners, the Ontario MOHLTC and an anonymous donor.
Data sharing: The data set from this study is held securely in coded form at ICES. Although data-sharing agreements prohibit ICES from making the data set publicly available, access may be granted to those who meet prespecified criteria for confidential access, available at www.ices.on.ca/DAS. The full data set creation plan and underlying analytic code are available from the authors on request, with the understanding that the computer programs may rely on coding templates or macros that are unique to ICES and are therefore inaccessible or may require modification.

Acknowledgments: The authors thank Kinwah Fung for her contributions to methodologic oversight, and the Ontario Ministry of Health and Long-Term Care for their data.

Disclaimer: This study was supported by ICES, which is funded by an annual grant from the Ontario Ministry of Health and Long-Term Care (MOHLTC). The opinions, results and conclusions reported in this paper are those of the authors and are independent from the funding sources. No endorsement by ICES or the Ontario MOHLTC is intended or should be inferred. Parts of this material are based on data or information compiled and provided by the Canadian Institute for Health Information $(\mathrm{CIHI})$ and Service Ontario. However, the analyses, conclusions, opinions and statements expressed herein are those of the authors and not necessarily those of $\mathrm{CIHI}$ or Service Ontario.

Accepted: June 23, 2020

Correspondence to: Paul Kurdyak, Paul.Kurdyak@camh.ca 